\title{
Urban Sprawl and Loss of Agricultural Land in Peri-urban Areas of Lagos*
}

Samuel Dekolo Examinations of 'peri-urban' remain elusive and

University of Lagos, Lagos State Polytechnic,

Nigeria

E-mail:

sdekolo@unilag.edu.ng

Leke Oduwaye

University of Lagos, Nigeria

Immaculata Nwokoro

University of Lagos, Nigeria often neglected by urban planners. However, these transitional zones are constantly under pressure by increasing populations from inner cities and migrants from the surrounding rural areas. The result in most developing countries is uncontrolled or unplanned landscapes. Although urban growth is inevitable and land use changes are imminent as peri-urban expansions of cities, peri-urban areas are pivotal regarding the agricultural resources necessary to urban survival. Understanding the development patterns, emerging urban forms, and their influences on peri-urban areas require an understanding of development decisions. Such knowledge will help decision makers and urban managers develop appropriate policies to address growth in 'edge' cities. This study focuses on the organic growth of Ikorodu, a peri-urban municipality on the outskirts of Lagos that emerged from a sleepy farming community with a population less than 100,000 in 1975 to a vibrant city exceeding one million residents in 2015. The study employs a multi-temporal remote sensing and GIS analysis to

Keywords: detect the urban pattern and emergent form over a

sprawl, 40-year period from 1975 to 2015. An empirical peri-urban, analysis was performed using survey data on 300 remote sensing, homeowners in 61 communities to identify the fractals, influences of rapid growth and the responses of policy planners to the city's growth.

\footnotetext{
* This work is part of postgraduate research work carried out at the University of Lagos and presented at the International Seminar for Urban Form (ISUF) Rome, September 22 $2^{\text {nd }}-26^{\text {th }} 2015$, Faculty of Architecture, "Sapienza" University of Rome, Italy with funding from the Tertiary Education Trust Fund (TETFUND).
} 


\section{Introduction}

Urban growth in developing countries is dynamic and diverse; however, it is also disordered and disturbing. This growth is synonymous with sprawling fractals compared to the compact aggregations observed in the global North. The cost of sporadic growth in rapidly growing metropolitan areas is enormous, evidenced by consistent diminution of high-quality agricultural land and forests in the peripheral areas of cities and in rural areas by residential and manufacturing incursions (JiangDeng-Seto 2013, Martellozo et al. 2014). This process is referred to as 'periurbanization', and it mostly occurs in non-contiguous transitional zones between rural areas and cities (Iaquinta-Drescher 2000). Significant research has focused on the peri-urban interface, land use changes, and agricultural economics (Bell-Irwin 2002, Theobald 2005, Buxton-Low 2007, Lawanson-Yadua-Salako 2012).

Studies of urban forms, spatial patterns, and processes that influence these changes are rooted in North American and European scholarship. Examples include Burgess' work on the concentric growth of cities inferred from his research in Chicago and Hoyt's 'Sector Theory' regarding the influences of linkages and geographic features on urban structures. Other notable studies are Christaller's 'Central Place Theory', which emphasises the spatial equilibrium of urban structure and pattern, and Harris and Ullman's 'Multi-Nuclei Theory' of the polycentricism of cities. However, since the 1990s, studies on urban morphology have focussed on cities' fractal geometry (Batty-Longley 1994, Frankhauser 1994, Terzi-Kaya 2011). Few studies have investigated the morphological processes associated with periurbanization (Tannier-Pumain 2005, Lagarias 2007, Terzi-Kaya 2011). The relevant studies focused on the global North and did not comparatively assess similarities and differences between Northern and Southern countries in the speed, scope, and experience of peri-urbanization (Fragkias et al. 2012). Therefore, a need exists for studies on peri-urbanization and morphological processes in the African context to close the gap in the literature. Furthermore, those empirical studies that examined the mechanisms of and policy responses to peri-urban growth in African cities are not well documented. This study aims to identify the urban pattern and emergent form of a non-contiguous peri-urban city on the outskirts of the Lagos metropolis over a 40-year period spanning 1975 through 2015. The study further aims to identify the factors related to the land use pattern and the responses of land use planners to these emerging forms.

\section{The Study Area}

This study's site is Ikorodu, a municipality (Local Government Area) on the outskirts of Lagos Metropolis approximately $36 \mathrm{~km}$ northeast of Lagos between longitude $3.43^{\circ}$ $\mathrm{W}$ and $3.7^{\circ} \mathrm{W}$ and latitude $6.68^{\circ} \mathrm{N}$; it is $6.53^{\circ}$ north of the equator. Its area is approximately $396.5 \mathrm{~km}^{2}$, with landmass of $368.5 \mathrm{~km}^{2}$. Since its creation in 1968 as

Regional Statistics, Vol 5, No 2. 2015: 20-33; DOI: 10.15196/RS05202 
one of five administrative divisions of Lagos State, Ikorodu has been characterised by its extensive farmlands. It includes several hectares of land for farming settlements acquired by the defunct government of Western Region of Nigeria and, in the 19802000 Regional Plan of Lagos State, about $180 \mathrm{~km}^{2}(49 \%)$ of its landmass was zoned for agricultural use. Although farming, fishing, and trading are the basic means of indigenous livelihood, a 1,582.27 ha industrial estate (the largest in Nigeria) established by the Lagos State Government in 1976 is a major pull factor leading to population growth. Other pull factors include a light port terminal at Ipakodo, the expanded Lagos-Ikorodu road, and established secondary and tertiary sector activities. The municipality recorded a 186\% population increase between the 1991 and 2006 censuses (i.e., from 184,674 to 527,917), and its population is estimated at 1.5 million based on the United Nations Urbanizations Prospects projection for Lagos State of 12.9 million (United Nations, Department of Economic and Social Affairs, Population Division, 2014).

Figure 1

\section{Map Showing the Study Area within the Lagos Metropolitan Area}

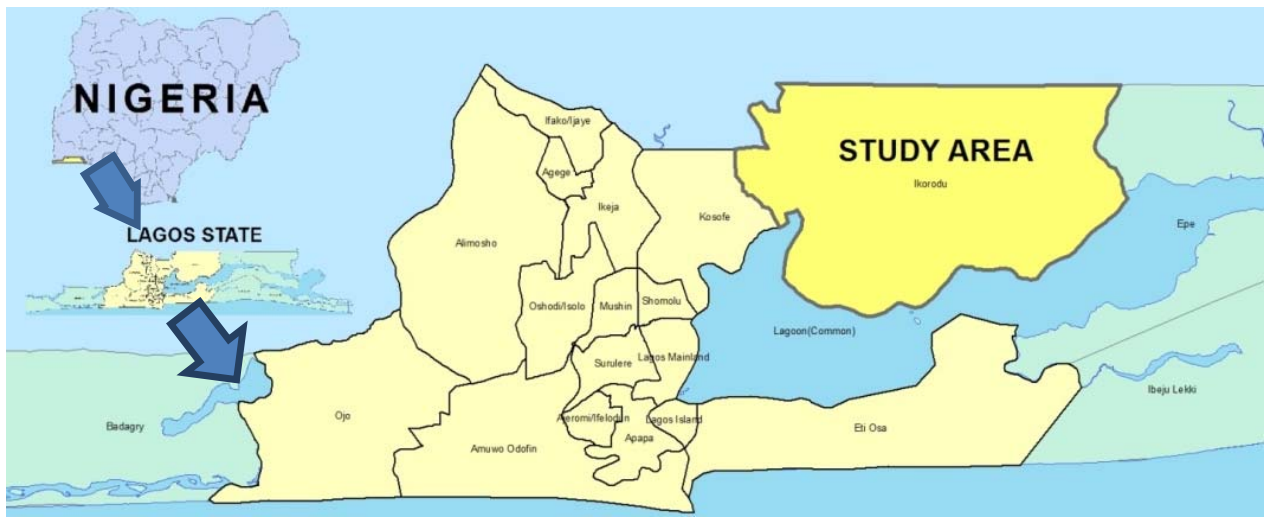

\section{Methodology}

Fractal analysis has been widely used during the past three decades to shed light on urban patterns and morphologies. Fractals suggest complexities, hierarchies, and selfsimilarities, across scales and time, and they have been helpful for understanding periurbanization processes (Batty-Longley 1994, Tannier-Pumain 2005, ThomasFrankhauser-De Keersmaecker 2007, Lifeng-Fang-Zengxiang-Xiaoli 2015). Fractal analysis describes spatial arrangements of built-up areas as well as their quality. Highly fragmented built-up areas representing sprawling patterns have low fractal dimensions, whereas compaction and regularity yield higher figures. Fractal dimensions could range from 1 to 2 for simple geometric objects and from 0 to 2 for urban geometry, similar to Sierpinski carpets (Tannier-Pumain 2005). 
This study employed a five-year interval multi-temporal analysis; the data used were multi-spectral remote sensing data for the available periods $(1984,1990,2000$, 2006, 2011, and 2015) as shown in Table 1. However, Landsat imageries for 1975, 1980, and 1995 were not available, and the Land Use/Land Cover Map of 1976/1978 was used for 1975 and 1980. RGB composite rasters were developed from multispectral Landsat imageries that were further classified by means of an ISODATA unsupervised algorithm.

Table 1

Data Source

\begin{tabular}{c|c|c|c|c|c|c|c}
\hline $\begin{array}{c}\text { Acquisition } \\
\text { Date }\end{array}$ & $\begin{array}{c}\text { Satellite } \\
\text { Number }\end{array}$ & $\begin{array}{c}\text { Sensor } \\
\text { Type }\end{array}$ & $\begin{array}{c}\text { WRS } \\
\text { Path/ } \\
\text { Row }\end{array}$ & $\begin{array}{c}\text { UTM } \\
\text { Zone }\end{array}$ & Datum & $\begin{array}{c}\text { Spatial } \\
\text { Reso- } \\
\text { lution (M) }\end{array}$ & $\begin{array}{c}\text { Sources } \\
\text { and Year }\end{array}$ \\
\hline $18-12-1984$ & Landsat 5 & TM & $191 / 55$ & $31 \mathrm{~N}$ & WGS84 & $28.5-30$ & $\begin{array}{c}\text { USGS, } \\
1984\end{array}$ \\
\hline $27-12-1990$ & Landsat 4 & TM & $191 / 55$ & $31 \mathrm{~N}$ & WGS84 & $28.5-30$ & $\begin{array}{c}\text { USGS, } \\
1990\end{array}$ \\
\hline $06-02-2000$ & Landsat 7 & ETM+ & $191 / 55$ & $31 \mathrm{~N}$ & WGS84 & $28.5-30$ & $\begin{array}{c}\text { USGS, } \\
2000\end{array}$ \\
\hline $07-12-2006$ & Landsat 7 & ETM+ & $191 / 55$ & $31 \mathrm{~N}$ & WGS84 & $28.5-30$ & $\begin{array}{c}\text { USGS, } \\
2006\end{array}$ \\
\hline $03-01-2011$ & Landsat 7 & ETM+ & $191 / 55$ & $31 \mathrm{~N}$ & WGS84 & $28.5-30$ & $\begin{array}{c}\text { USGS, } \\
2011\end{array}$ \\
\hline $06-01-2015$ & Landsat 8 & $\begin{array}{c}\text { OLI- } \\
\text { TIRS }\end{array}$ & $191 / 55$ & $31 \mathrm{~N}$ & WGS84 & $28.5-30$ & $\begin{array}{c}\text { USGS, } \\
2015\end{array}$ \\
\hline
\end{tabular}

Supporting Spatial Data /Demographic Data

\begin{tabular}{c|c|c}
\hline $1976 / 78$ & Land Use/Land Cover Map & FORMECU, 1978 \\
\hline 1980 & The Lagos State Regional Plan (1980-2000) & $\begin{array}{c}\text { Doxiadis Associates, } \\
1980\end{array}$ \\
\hline & National Population Census 1963, 1991, 2006 & NPC 1991, 2006
\end{tabular}

Data on built-up urban areas were extracted from ISODATA classified rasters by coding built-up pixels as black and other land cover types as white. The classified images were subsequently analysed for their fractal dimensions using the software package Fractalyse (version 2.3.2). The software uses numerous methods to measure fractal dimensions; these include box counting, radius mass, dilation, and correlation. For this study, the radial mass measure was employed, which analyses by the iteration principle whereby the total number of built-up pixels are counted within the circle from a specified point (the counting centre).

As shown in Figure 2, urban core area of Ikorodu shown on the 1976/1978 land use map is the counting centre. At each step, the radius $r$ is gradually increased, and the total number of occupied points $N(\varepsilon)$ inside the circle is counted (where $\varepsilon$ equals $2 . r+1)$.

Regional Statistics, Vol 5, No 2. 2015: 20-33; DOI: 10.15196/RS05202 
Screen print of radial mass method in Fractalyse

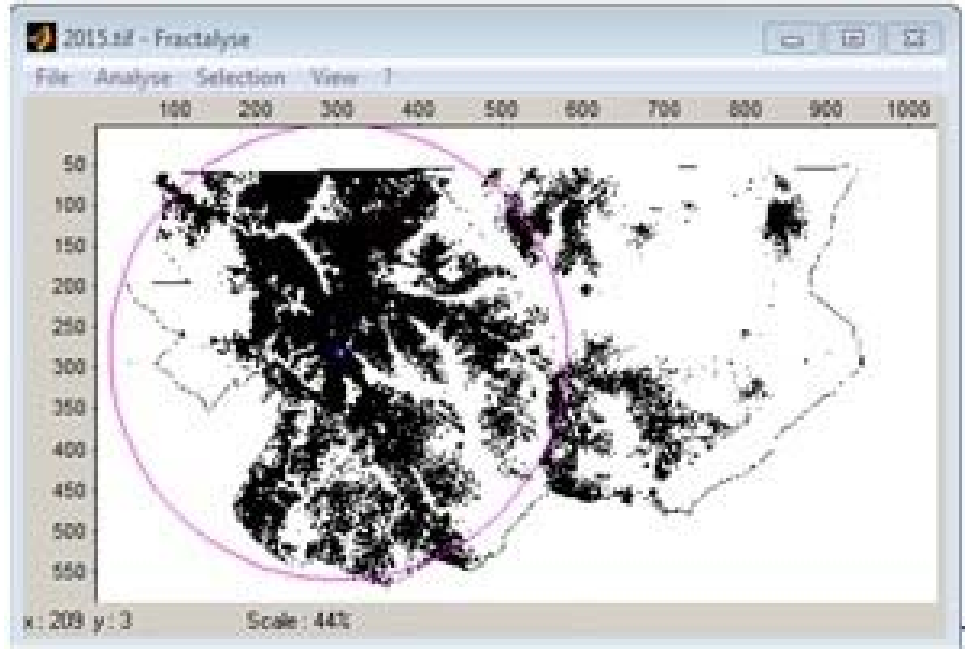

e series of points obtained is represented by a Cartesian graph (Figure 3) with the $\mathrm{Y}$-axis corresponding to the number of counted elements $(N)$ and the $\mathrm{X}$-axis corresponding to the value of the reference element $\varepsilon$.

Figure 3

\section{Screen print of fractal analysis ' $D$ ' estimation in Fractalyse}

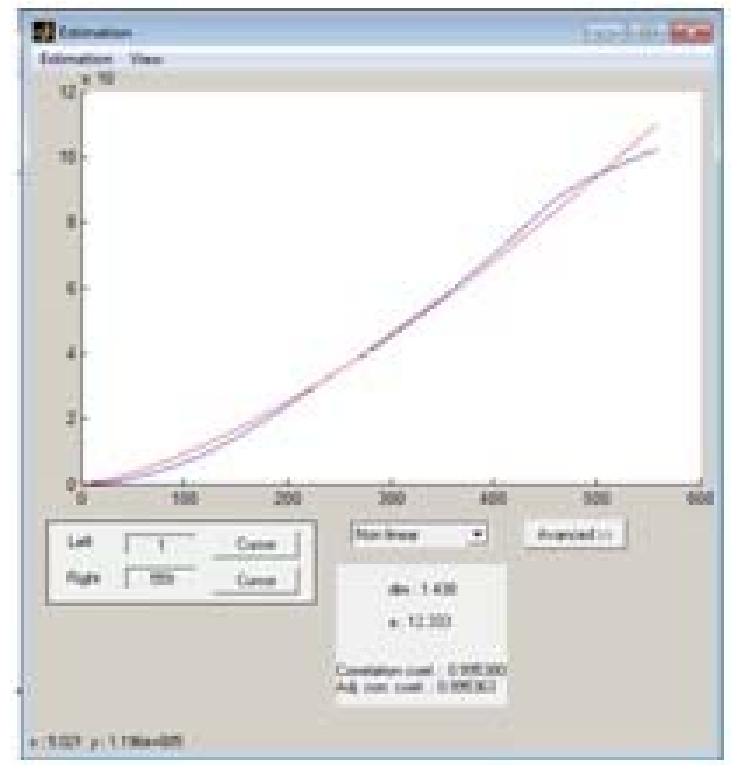

Regional Statistics, Vol 5, No 2. 2015: 20-33; DOI: 10.15196/RS05202 
The empirical curve of the plot is then fitted to the estimated curve. A good fit indicates fractality; however, the quality of the estimation was verified by correlation analysis. A non-linear regression derives the value of the three parameters: $a, D$, and $c$, where $a$ is the pre-shape factor and $c$ is the point of origin on the Y-axis $(c=0)$ (Tannier-Pumain 2005). Thus, the fractal dimension $D$ is determined by the following equation:

where

$$
N=a \varepsilon^{D}+c
$$

$$
\varepsilon=2 . r+1
$$

Fractal dimension values close to two indicate regularity and orderly development whereas values close to one or zero indicate a sprawling and leapfrogging pattern of development. Furthermore, to ascertain the extent of sprawling development in the agricultural land, the urban extent layers were extracted in ArcGIS by intersecting geoprocessing with the agricultural land zone of the Regional Plan of Lagos State of 1980.

The relationship between the fractal dimension and the dynamics index of agricultural change was determined by regression analysis. The dynamic index was calculated (Zhu-Li 2003) to derive change in allocated agricultural land by the following equation:

$$
C D I=\frac{U_{a}-U_{b}}{U_{a}} \times 100 \%
$$

where $C D I$ is the change dynamic index for a single land use $U$ between starting period $a$ and ending period $b$.

\section{Morphological Process and Spatial Patterns}

The peri-urbanization process in Ikorodu over the past four decades shows dynamic urban changes and a sprawling development pattern. The fractal analysis of the study area based on remotely sensed images from 1984 to 2015 found steady organic growth in which sprawling precedes infilling. The values of the fractal dimension increased steadily from the lowest 0.41 in 1975 to a low 1.44 value in 2015 (see Table 2). Values less than one indicate lack of connectivity among elements in the built-up space, whereas values slightly greater than one indicates sprawl (Thomas-FrankhauserBiernacki 2008).

As seen in Table 2, the highest fractal dimension $(D)$ value in this study is 1.44, which indicates sprawl. The implication of this pattern is loss of valuable agricultural land to urban development, which could have major repercussions on sustainable food production and security.

The continuous urban expansion of the past four decades in Ikorodu shown in Table 2 has resulted in no less than $25.8 \%$ of the total land area allocated to agriculture and food production. Moreover, the annual urban growth rate in the study area tripled from 316 ha/year in 2011 to 1171 ha/year in 2015, creating significant concern.

Regional Statistics, Vol 5, No 2. 2015: 20-33; DOI: 10.15196/RS05202 


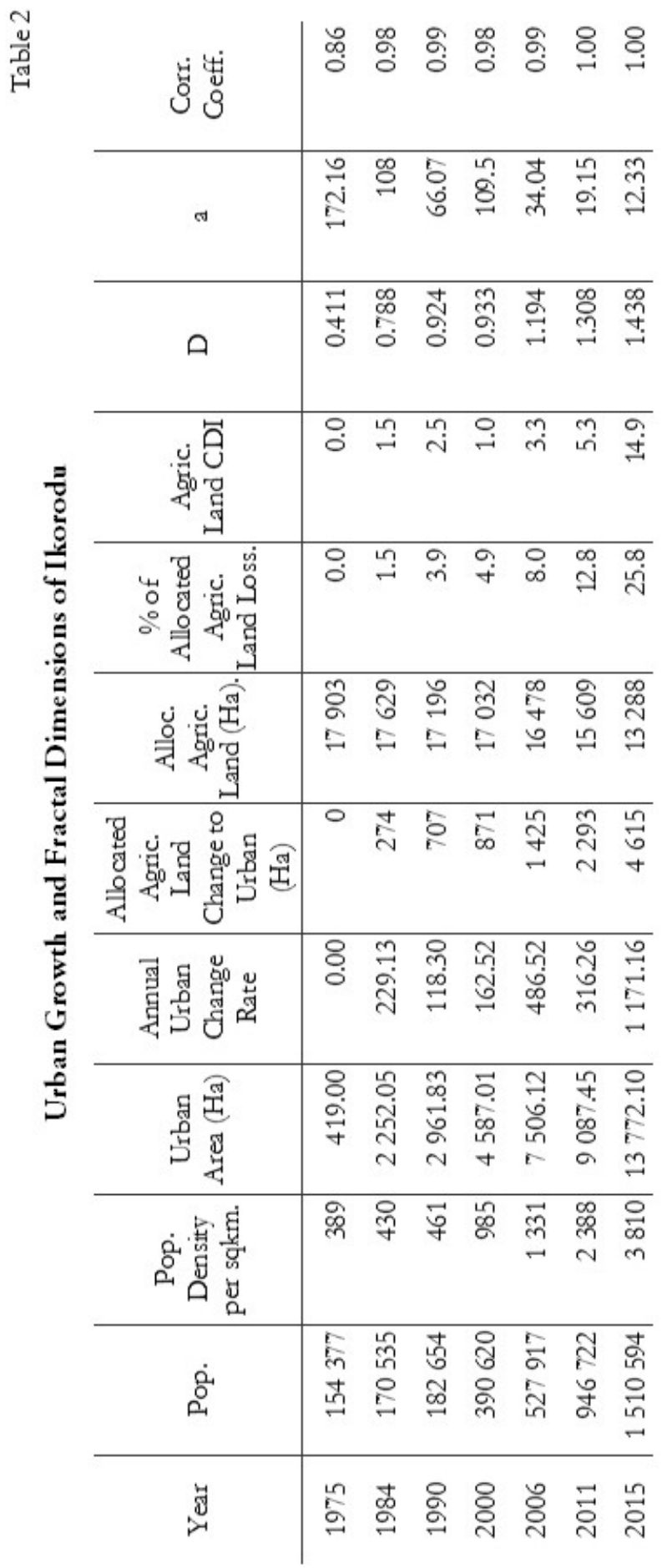


The dotted lines in Figure 4 represents areas zoned for agricultural land use in the regional plan. This area is about 18,000 hectares of land and approximately 49 percent of the total local government land mass. However, in order to determine the extents of urban development in the areas zoned for agriculture, urban pixels in the classified imageries were extracted for periods under consideration and layers were created in ArcGIS.

The result indicates that there has been uncontrolled urban development on land zoned or allocated for agriculture in the regional plan for Lagos State. Figure 4 also reveals that these uncontrolled expansion has taken place especially in the post 2006 periods, as patches indicates more diminution of agricultural lands after this period. suggests that controls on development have been ineffective and urban spatial expansion has not followed the requirements of the existing regional plan.

Figure 4

\section{Map of Ikorodu Showing Urban Growth and Extents in Agricultural Zone}

(1984-2015)

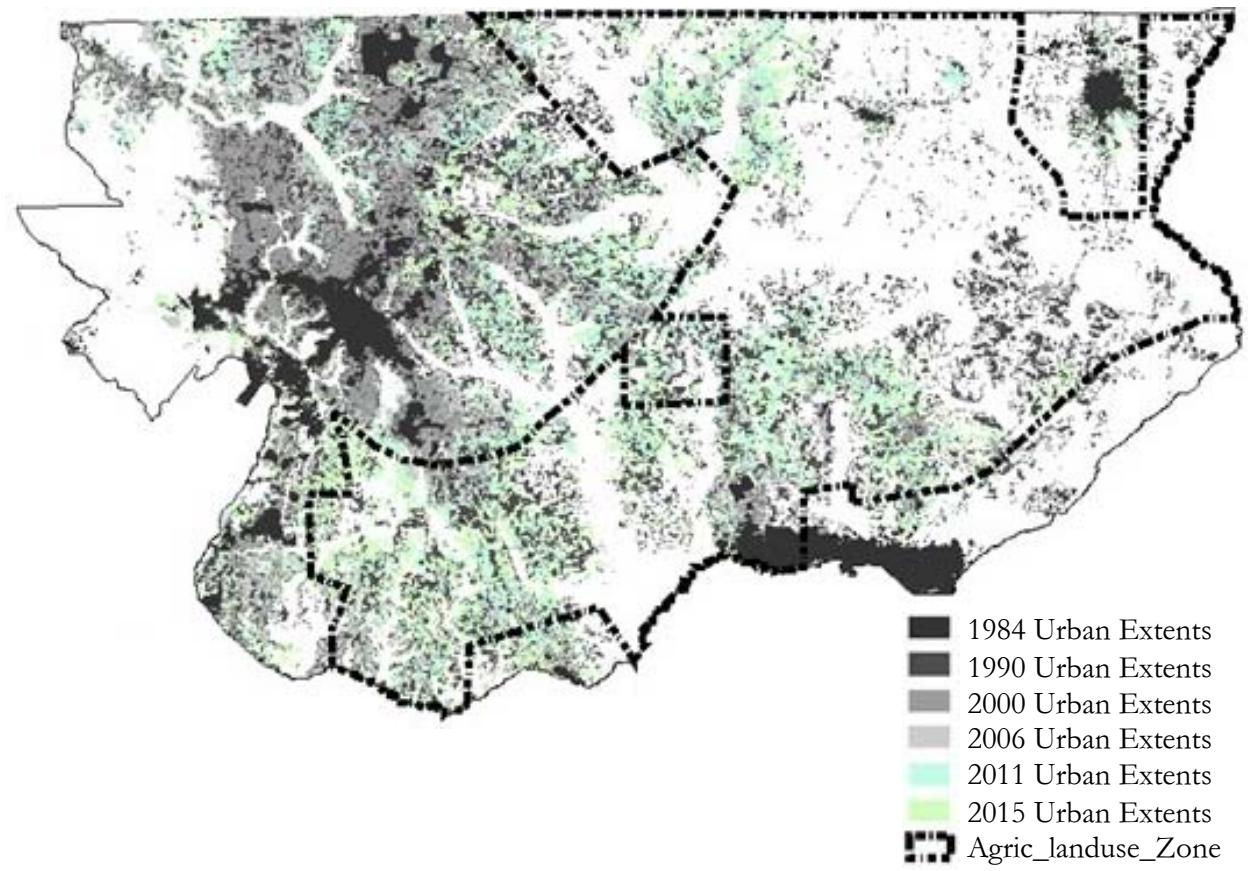

A regression model was applied to determine the relationship between the fractal dimension and the change dynamic index for allocated agricultural lands. The regression model results found a strong positive correlation of $78 \%$ between fractal dimension $D$ and the change dynamic index (CDI) for allocated agricultural land such that $60 \%$ of the variation in agricultural land is explained by the sprawling expansion of urban land uses $(r=0.78, p=.04)$. In order to determine the statistical significance

Regional Statistics, Vol 5, No 2. 2015: 20-33; DOI: 10.15196/RS05202 
of the variation, a one way F-Test Analysis of Variance (ANOVA) was used; The result indicated statistical significance $(\mathrm{F}=7.67$ and $\mathrm{P}<0.05)$.

Table 3

\section{Summary Outputs:}

\section{Regression Statistics for Agricultural Land CDI and Fractal Dimension 'D'}

\begin{tabular}{|c|c|c|c|c|c|c|c|c|}
\hline \multicolumn{5}{|c|}{ Regression Statistics } & & & & \\
\hline \multicolumn{3}{|c|}{ Multiple R } & & 0.776 & & & & \\
\hline \multicolumn{3}{|l|}{ R Square } & & 0.602 & & & & \\
\hline \multicolumn{3}{|c|}{ Adjusted R Square } & & 0.522 & & & & \\
\hline \multicolumn{3}{|c|}{ Standard Error } & & 3.502 & & & & \\
\hline \multicolumn{3}{|c|}{ Observations } & & 7 & & & & \\
\hline \multicolumn{9}{|c|}{ ANOVA } \\
\hline \multicolumn{2}{|r|}{$d f$} & \multicolumn{2}{|c|}{ SS } & $M S$ & $F$ & \multicolumn{2}{|c|}{ Significance F } & \\
\hline \multicolumn{2}{|c|}{ Regression } & & 92.775 & 92.775 & 7.564 & \multicolumn{2}{|c|}{0.040} & \\
\hline \multicolumn{2}{|l|}{ Residual } & & 61.327 & 12.265 & & & & \\
\hline \multirow[t]{2}{*}{ Total } & 6 & & 154.101 & & & & & \\
\hline & Coeff. & S.E. & tStat & $\begin{array}{c}P- \\
\text { value }\end{array}$ & $\begin{array}{l}\text { Lower } \\
95 \%\end{array}$ & $\begin{array}{l}\text { Upper } \\
95 \%\end{array}$ & $\begin{array}{l}\text { Lower } \\
95.0 \%\end{array}$ & $\begin{array}{l}\text { Upper } \\
95.0 \%\end{array}$ \\
\hline $\begin{array}{l}\text { Intercept } \\
\text { Fractal } \\
\text { Dim. (D) }\end{array}$ & $\begin{array}{l}-7.247 \\
11.301\end{array}$ & $\begin{array}{l}4.315 \\
4.109\end{array}$ & $\begin{array}{r}-1.680 \\
2.750\end{array}$ & $\begin{array}{l}0.154 \\
0.040\end{array}$ & $\begin{array}{r}-18.338 \\
0.738\end{array}$ & $\begin{array}{r}3.845 \\
21.863\end{array}$ & $\begin{array}{r}-18.338 \\
0.738\end{array}$ & $\begin{array}{r}3.845 \\
21.863\end{array}$ \\
\hline
\end{tabular}

Figure 5 shows that sprawled areas are initially dispersed, but due to infilling or increased densities such areas becomes compact, the values of the fractal dimension $(D)$ tend to increase in relationship with increased loss of peri-urban agricultural land. Although this pattern of growth is historically observed in most cities' growth ( $D$ increases over time), the important question concerns the extent to which the growth is guided by or compliant with existing regional plans. 
Figure 5

Regression model showing a positive correlation between Fractal Dimension and Agricultural land Change Dynamic Index during the study period

(1984-2015)

Fractal Dim. (D) Line Fit Plot

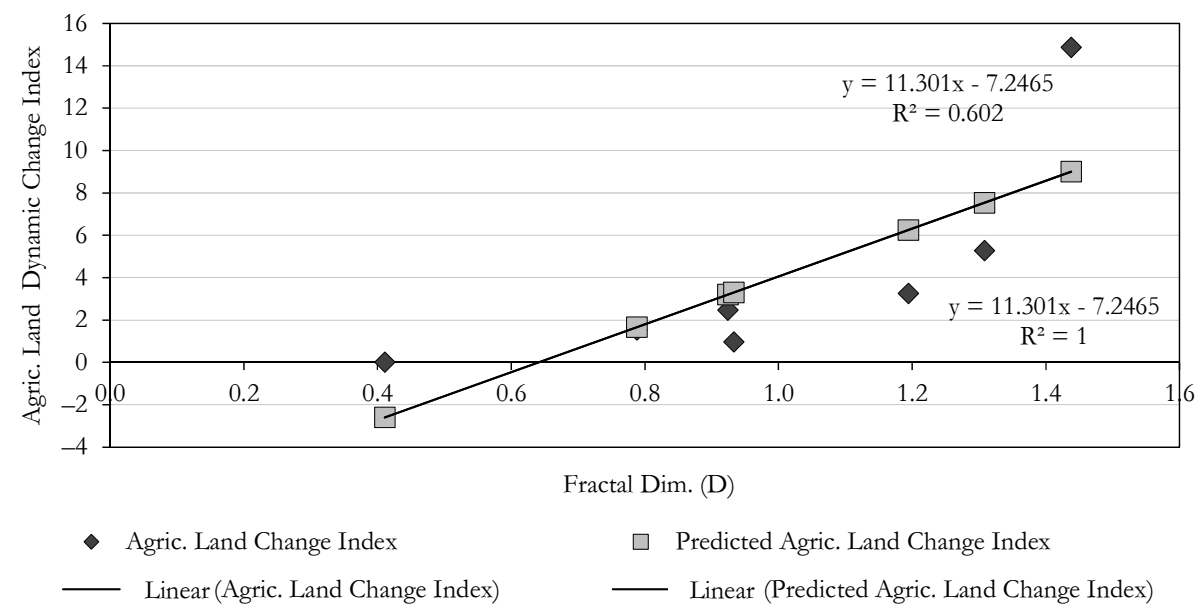

e unguided spatial pattern found by this study is inevitable because the survey finds that only $39 \%$ of the respondents had obtained building permits, and inspectors of the development controls or planning agencies had never visited the remaining $61 \%$. The ineffective development control system is partly responsible for the uncontrolled expansion.

\section{Influences on the Peri-urban Growth and Spatial Pattern}

Urban morphology cannot be divorced from anthropogenic factors. Therefore, questionnaires were distributed to 300 homeowners in an estimated population of 120,000 housing units across 61 communities in the six Local Council Development Areas (LCDAs) of the study area (the total number of homeowners identified in 2012 by the Lagos State Government for Land Use Charge was 89, 609).

To determine the influences of peri-urban growth and the effectiveness of existing land use planning policies for managing the sprawling pattern of development, questions were asked regarding: (1) the motivations for developing in the peri-urban municipality, (2) types of land use, (3) timing of property development, and (4) awareness of planning regulations and development control agencies' controls on home construction. About 90\% (270 homeowners) responded and data was analysed using the SPSS and Excel statistical programs.

Regional Statistics, Vol 5, No 2. 2015: 20-33; DOI: 10.15196/RS05202 
A factor analysis was performed to determine key influences on urban morphology, and the suitability of the data was determined by the Kaiser-MeyerOlkin Measure of Sample Adequacy (KMO) and Bartlett's test of sphericity. The $\mathrm{KMO}$ result is 0.930 and Bartlett's significance value is zero. This initial result confirms the suitability of the data for factor analysis (the KMO statistic must be no greater than 0.6 and Bartlett's significance value must be 0.5 or less). Three factors with eigenvalues greater than 1.0 explained $59.9 \%$ of the variation in the data; however, using the scree plot and the component matrix, two factors have the highest loadings and explain 54.2\%. Therefore, Principal Components Analysis with Direct Oblimin rotation and Kaiser Normalization were applied to extract the highest loading factors, which were identified as the major influences on morphological changes. Furthermore, descriptive and inferential statistics were used to assess the effects of implemented policies on managing sprawl and land use change.

Table 4

Pattern Matrix*

\begin{tabular}{|c|c|c|}
\hline \multirow{2}{*}{ Reasons for residential development } & \multicolumn{2}{|c|}{ Component } \\
\hline & 1 & 2 \\
\hline 1 Less time and money spent from location & .899 & \\
\hline 2 Proximity to work & .888 & \\
\hline 3 Good health and less stress than city & .829 & \\
\hline 4 Lower cost of living than city & .731 & \\
\hline 5 Purchased through cooperative & .725 & \\
\hline 6 Closeness to leisure and nature & .711 & \\
\hline 7 Land speculation/investment & .673 & \\
\hline 8 Affordable land & .582 & \\
\hline 9 Proximity to family and friends & .451 & .304 \\
\hline 10 Obtained by inheritance & .444 & \\
\hline 11 Invited to purchase by someone close & .377 & \\
\hline 12 Personal achievement of a lifetime & & .766 \\
\hline 13 Proximity of site to urban infrastructure & & .750 \\
\hline 14 Site access to transportation infrastructure & & .727 \\
\hline 15 Security of land tenure & & .718 \\
\hline 16 Adequate security of life and property & & .683 \\
\hline 17 Inheritance to leave for children & & .494 \\
\hline 18 Land free of government acquisition & .301 & .482 \\
\hline $\begin{array}{l}\text { Extraction Method: Principal Component Analysis. } \\
\text { Rotation Method: Oblimin with Kaiser Normalization. } \\
{ }^{*} \text { Rotation converged in seven iterations. }\end{array}$ & & \\
\hline
\end{tabular}


The factors that influence continuous growth were reduced from 18 to 10 using Principal Component Analysis (Table 4 below); however, three of the highest loading factors (those $>0.70$ ) were selected as the major influences on peri-urban growth in Ikorodu. These factors are: (1) less time and money spent on transportation from location (0.899), (2) proximity to work (0.888), and (3) good health and less stress than the city (0.829). That proximity to work and ease of transportation are principal influencing factors is corroborated by the survey results, which indicate that $50 \%$ of the Ikorodu respondents reported that their workplaces are located in the Ikorodu municipality. As stated above, Ikorodu has the single largest industrial estate in Nigeria and is home to many secondary and tertiary activities that attract housing and other types of development.

\section{Conclusion}

This study examined the growth and morphology of a peri-urban city spanning a period of forty years. The results of its fractal dimension analysis indicate rapid urban changes that correlate with the pace of agricultural land loss. Moreover, ineffective controls and lack of policy implementation or enforcement has resulted in sprawling and unguided development in the urban fringe areas of the Lagos metropolitan area of Ikorodu. The implication of this continuous change in the absence of archaeological evidence and the confidence placed in this study's inferences suggests that these land use changes of uncontrolled expansion result in the diminution of precious agricultural and forested lands.

Previous efforts have been made to quantify global peri-urban croplands (TheboDrechsel-Lambin 2014). However, this study attempted to quantify the allocated agricultural land and found that such lands in the study area were reduced by the significant extent of $25 \%$. If nothing is done to alter that trend, the food security of the Lagos metropolitan region could be at risk. Therefore, we recommend that urban and regional planners in developing countries similar to Nigeria incorporate real-time remote sensing data and geospatial technology to monitor urban expansion, particularly in the peri-urban areas, which are presently neglected. Furthermore, comparative morphological studies of other peri-urban settlements in developing countries should be undertaken to develop theories relevant to these phenomena.

Regional Statistics, Vol 5, No 2. 2015: 20-33; DOI: 10.15196/RS05202 


\section{REFERENCE}

Batty, M. - Longley, P. A. (1994): Fractal Cities: A Geometry of Form and Function Academic Press, London.

BeLl, K. P. - IRwin, E. G. (2002): Spatially Explicit Micro-Level Modelling of Land Use Change at the Rural-Urban Interface Agricultural Economics 27 (3): 217-232.

Burgess, E. W. (1925/1967): The Growth of the City: An Introduction to a Research Project In: Park, R. E. E. - Burgess, W. - McKenzie, R. D. The City pp. 47-62., University of Chicago Press, Chicago, IL.

Buxton, M. - Low, C. D. (2007): Change in Peri-urban Australia: Implications for Land Use Policies State of Australian Cities (SOAC) Conference. Adelaide: Australian Cities and Regions Network) from http://soac.fbe.unsw.edu.au/2007/papers/include.asp (downloaded: June 12, 2012).

Christaller, W. (1933): Die zentralen Orte in Sud deutschland Prentice Hall, Inc., Englewood Cliffs, NJ.

Fragkias, M. - Langanke, T. - Boone, C. G. - HaAse, D. - Marcotullio, P. J. Munroe, D. -Simon, D. (2012). Land Teleconnections in an Urbanizing World - A workshop Report GLP-IPO/UGEC-IPO, Copenhagen.

Frankhauser, P. (1994): La Fractalité des Structures Urbaines Economica, Paris.

Harris, C. D. - Ullman, E. L. (1945): The Nature of Cities Annals of the American Academy of Political and Social Science 242: 7-17.

HoYT, H. (1939): The Structure and Growth of Residential Neighborhoods in American Cities U.S. Federal Housing Administration, Washington.

IAQUiNTA, D. L. - Drescher, A. W. (2000): Defining periurban: understanding rural-urban linkages and their connection to institutional contexts Tenth World Congress of the International Rural Sociology Association International Rural Sociology Association, Rio de Janeiro.

JiAng, L. - Deng, X. - SETO, K. (2013): The Impact of Urban Expansion on Agricultural Land Use Intensity in China Land Use Policy 35: 33-39

LAgArias, A. (2007): Fractal Analysis of the Urbanization at the Outskirts of the City: Models, Measurement and Expalnations Cyber Geo: European Journal of Geography, document 391.

Lagos State Government (2013): Digest of Statistics 2013 Lagos Bureau of Statistics, Lagos.

LAWANSON, T. - YAdUA, O. - SALAKO, I. (2012): Environmental Challenges of Peri-Urban Settlements in the Lagos Megacity In: SCHrenk, M. -Popovich, V. V. - ZEILE, P. -Elisei, P. (Ed.) 17th International Conference on Urban Planning, Regional Development and Information Society pp. 275-285., CORP Association, Schwechat.

Lifeng, S. - FANG, L. - ZengXiAng, Z. - XiAoli, Z. (2015): Monitoring Urban Expansion and Morphology Changes of Tangshan by Using Remote Sensing In: Bian, F. Xie, Y. Geo-Informatics in Resource Management and Sustainable Ecosystem, Communications in Computer and Information Science 482: 625-634., Springer, BerlinHeidelberg.

Martellozo, F. - Ramankutty, N. - Hall, R. J. - Price, D. - Purdy, B. - Friedl, M. (2014): Urbanization and the Loss of Prime Farmland: A Case Study in the 
Calgary-Edmonton Corridor of Alberta Regional Environmental Change 15 (5):881893.

TANNIER, C. - Pumain, D. (2005): Fractals in Urban Geography: A Theoretical Outline and an Empirical Example Cybergeo: European Journal of Geography, document 307.

TERZI, F. - KAYA, H. S. (2011): Dynamic spatial analysis of urban sprawl through fractal geometry: the case of Istanbul Environment and Planning B: Planning and Design 38 (1): 175-190.

Thebo, A. L. - Drechsel, P.- Lambin, E. F. (2014): Global Assessment of Urban and Periurban Agriculture: Irrigated and Rainfed Croplands Environmental Research Letters 9 (11): 1-9.

Theobald, D. M. (2005): Landscape Patterns of Exurban Growth in the USA from 1980 to 2020 Ecology and Society 10 (1): 32-66.

Thomas, I. - Frankhauser, P. - Biernacki, C. (2008): The morphology of built-up landscapes in Wallonia (Belgium): A classification using fractal indices Landscape and Urban Planning 84 (2): 99-115.

Thomas, I. - Frankhauser, P. - De Keersmaecker, M.-L. (2007): Fractal Dimension Versus Density of the Built-up Surfaces in the Periphery of Brussels. Papers in Regional Science 86 (2): 287-308.

United Nations, Department of Economic and Social AfFiars, Population DIVISION. (2014): World Urbanisation Prospects: The 2014 Revision, CD-ROM Edition. United Nations, New York.

ZHU, H.-Y. - LI, X.-B. (2003): Discussion on the Index Method of Land Use Change Journal of Geographical Science 58 (5): 634-650.

Regional Statistics, Vol 5, No 2. 2015: 20-33; DOI: 10.15196/RS05202 